\title{
Field-Scale Evaluation of Biostimulation for Remediation of Uranium- Contaminated Groundwater at a Proposed NABIR Field Research Center in Oak Ridge, TN
}

Criddle, Craig S.

Stanford University

RESULTS TO DATE: A hydrologic, geochemical and microbial characterization of the Area 3 field site has been completed. The formation is fairly impermeable, but there is a region of adequate flow approximately 50 feet bgs. The experiment will be undertaken within that depth interval. Groundwater from that depth is highly acidic ( $\mathrm{pH} 3.2)$, and has high levels of nitrate, aluminum, uranium, and other heavy metals, as well as volatile chlorinated solvents (VOCs). Accordingly, an aboveground treatment train has been designed to remove these contaminants. The train consists of a vacuum stripper to remove VOCs, two chemical precipitation steps to adjust $\mathrm{pH}$ and remove metals, and a fluidized bed bioreactor to remove nitrate. The aboveground system will be coupled to a belowground recirculation system. The belowground system will contain an outer recirculation cell and a nested inner recirculation cell: the outer cells will be continuously flushed with nitrate-free treated groundwater. The inner cell will receive periodic inputs of uranium, tracer, and electron donor. Removal of uranium will be determined by comparing loss rates of conservative tracer and uranium within the inner recirculation cell.

DELIVERABLES: Over the past year, a detailed workplan was developed and submitted for regulatory approval. The workplan was presented to the Field Research Advisory Panel (FRAP), and after some extensive revision, the FRAP authorized implementation. Detailed design drawings and numerical simulations of proposed experiments have been prepared. System components are being prefabricated as skid-mounted units in Michigan and will be shipped to Oak Ridge for assembly. One manuscript has been submitted to a peer reviewed journal. This paper describes a novel technique for inferring subsurface hydraulic conductivity values. Two posters on this project were presented at the March 2002 NABIR PI meeting. One poster was presented at the Annual conference of the American Society for Microbiology in Salt Lake City, UT in May 2002.

COLLABORATIONS: Oak Ridge National Laboratory Phil Jardine Anthony Palumbo Craig Brandt 